\title{
Correction: Association of anxiety with subcortical amyloidosis in cognitively normal older adults
}

\author{
Bernard J. Hanseeuw ${ }^{1,2,3} \cdot$ Victoria Jonas $^{1} \cdot$ Jonathan Jackson $^{1} \cdot$ Rebecca A. Betensky ${ }^{4} \cdot$ Dorene $^{\text {M. Rentz }}{ }^{1,5,6,7}$. \\ Keith A. Johnson ${ }^{1,2,6} \cdot$ Reisa A. Sperling ${ }^{1,5,6} \cdot$ Nancy J. Donovan ${ }^{5,6,7,8}$
}

Published online: 11 December 2018

(c) The Author(s) 2018. This article is published with open access

Correction to: Molecular Psychiatry; https://doi.org/10.1038/ s41380-018-0214-2; published online 16 August 2018

This Article was originally published under Nature Research's License to Publish, but has now been made available under a CC BY 4.0 license. The PDF and HTML versions of the Article have been modified accordingly.
Open Access This article is licensed under a Creative Commons Attribution 4.0 International License, which permits use, sharing, adaptation, distribution and reproduction in any medium or format, as long as you give appropriate credit to the original author(s) and the source, provide a link to the Creative Commons license, and indicate if changes were made. The images or other third party material in this article are included in the article's Creative Commons license, unless indicated otherwise in a credit line to the material. If material is not included in the article's Creative Commons license and your intended use is not permitted by statutory regulation or exceeds the permitted use, you will need to obtain permission directly from the copyright holder. To view a copy of this license, visit http://creativecommons.org/licenses/by/4.0/.
Nancy J. Donovan

njdonovan@bwh.harvard.edu

1 Department of Neurology, Massachusetts General Hospital, Harvard Medical School, Boston, MA 02114, USA

2 Department of Radiology, Massachusetts General Hospital, Harvard Medical School, Boston, MA 02114, USA

3 Department of Neurology, Cliniques Universitaires Saint-Luc, Institute of Neurosciences, Université Catholique de Louvain, Brussels, Belgium

4 Department of Biostatistics, Harvard T.H. Chan School of Public
Health, Boston, MA 02115, USA

5 Center for Alzheimer Research and Treatment, Brigham and Women's Hospital, Harvard Medical School, Boston, MA 02115, USA

6 Department of Neurology, Brigham and Women's Hospital, Harvard Medical School, Boston, MA 02115, USA

7 Department of Psychiatry, Brigham and Women's Hospital, Harvard Medical School, Boston, MA 02115, USA

8 Department of Psychiatry, Massachusetts General Hospital, Harvard Medical School, Boston, MA 02114, USA 